\title{
Structural Characterization and Thermal Properties of the Anti-malarial Drug: Lumefantrine
}

\author{
Pramod B. Pansuriya, Glenn E.M. Maguire and Holger B. Friedrich* (iD ${ }^{\S}$ \\ School of Chemistry and Physics, University of KwaZulu-Natal, Westville Campus, Durban, 4000, South Africa. \\ Received 19 July 2019, accepted 7 October 2019.
}

\begin{abstract}
The anti-malarial lumefantrine was characterized in the solid as well as the solution state. The solid state analysis was carried out by single crystal X-ray diffraction (SCXRD), powder X-ray diffraction (PXRD), DSC, TG-DTG and ATR-IR. The single crystal structure of lumefantrine has been solved. The structure is stabilized via inter- as well as intra-C- $\mathrm{H}$...Cl interactions, intra hydrogen bonding $\mathrm{O}-\mathrm{H}$... $\mathrm{N}$ interactions and $\mathrm{C}-\mathrm{H}$... O weak interactions. The Hirshfeld surface intermolecular interactions have been studied using the crystal structure. Solution structure analyses have been done by NMR, COSY/NOESY, HSQC and mass spectrometry. The thermal properties were studied by solid-state differential scanning calorimetry and thermogravimetric analysis of the drug under nitrogen as well as in air.
\end{abstract}

KEYWORDS

Single crystal structure, lumefantrine, 2D NMR, DSC, PXRD.

\section{Introduction}

Malaria is a parasitic disease in humans, with transmission occurring in countries with a combined population of $c$. three billion people. It causes thousands of deaths each year. ${ }^{1}$ The disease is caused by protozoan parasites of the genus Plasmodium. This malarial parasite depends on both mosquitoes and humans for its cycle. At the same time, growing levels of drug resistance have resulted in significant mortality worldwide and much evidence has emerged on the resistance of Plasmodium falciparum to many antimalarial agents. ${ }^{2}$ Improving access to effective anti-malarial treatment is very important. In Africa and Asia, where the disease is most prevalent, limited health care infrastructure complicates efforts to predict clinical demand. As a result the combination of lumefantrine and artemether (Coartem and Riamet, Falcynate-LF) was developed as a fixeddose combination therapy (ACT) for the treatment of acute uncomplicated 'Plasmodium falciparum malaria'. The combination is a potent, synergistically active and well-tolerated malaria treatment, powerful towards areas of multi-drug resistance. ${ }^{3-5}$

Both the individual drugs were developed in China. Lumefantrine (benflumetol or CGP 56695) is purely synthetic and was synthesized in the 1970s by the Academy of Military Medical Sciences, in Beijing. It was registered in China for anti-malarial use in 1987. The World Health Organization's (WHO) prequalified 'Coartem' in 2001 as a fixed dose combination therapy for efficacy, safety and quality. From 2002, this medication was adopted by the WHO and UN agencies. ${ }^{6,7}$ Coartem is approved by the European Medicines Agency (EMA) and the U.S. Food and Drug Administration (FDA).

The oral drugs have a shelf life of only two years. ${ }^{8}$ Much work is in progress to improve shelf life, novel drug release, and delivery systems. For these purposes, a molecular level study is necessary. In the present research we report the molecular level structural investigation, as well as the thermal decomposition of lumefantrine using single crystal X-ray diffraction (SCXRD), powder X-ray diffraction (PXRD), NMR, 2D NMR,DSC, TG-DTG and an ATR-IR study.

\section{Experimental}

\subsection{Materials}

The reagents and solvents were obtained from commercial sources in analytical grade. They were used without further purification. The melting point was recorded on an Ernst Leitz Wetzlar hot-stage microscope. It is uncorrected. Suitable crystals for X-ray diffraction were obtained at room temperature by slow evaporation using a mixture of dichloromethane and ethyl acetate.

\subsection{Methods}

\subsubsection{X-ray Diffraction Studies}

The crystal evaluation and data collection were done on a Bruker KAPPA APEXII DUO diffractometer using graphitemonochromated Mo K $\alpha$ radiation $(\lambda=0.71073 \AA)$ at $173(2) \mathrm{K}$. The reflections were successfully indexed by an automated indexing routine built into the APEXII program suite. ${ }^{9}$ The program SAINT+ was used for data reduction. ${ }^{10}$ The data were scaled and absorption correction performed using SADABS. The structure was solved by direct methods using SHELXS and refined by the full-matrix least-squares method based on $\mathrm{F}^{2}$ using SHELXL-97. ${ }^{11}$ Non-H atoms were first refined anisotropically. The program Olex2 was used to prepare molecular graphic images. ${ }^{12}$ All $\mathrm{H}$ atoms, except $\mathrm{H} 1$, were placed in idealized positions and refined in riding models with $U_{\text {iso }}$ assigned to 1.2 or 1.5 times the values of their parent atoms and constraint distances of $\mathrm{C}-\mathrm{H}$ ranging from $0.95 \AA$ to $1.00 \AA$ A. The hydrogen $\mathrm{H} 1$ was located in the electron difference maps and refined with the simple bond constraint $\mathrm{d}(\mathrm{O} 1-\mathrm{H} 1)=0.970(5) \AA$.

The PXRD pattern of the powder samples was obtained at room temperature using a Bruker D8 Advance diffractometer with $\mathrm{Cu} \mathrm{K} \alpha$ radiation $(1.54 \mathrm{~nm})$, at $40 \mathrm{kV}$ and $40 \mathrm{~mA}$. Accurately weighed $300 \mathrm{mg}$ of powder was loaded in a $25 \mathrm{~mm}$ poly-methyl methacrylate (PMMA) holder and gently pressed using a clean glass slide to ensure coplanarity of the powder surface with the 
surface of the holder. The diffractogram was obtained in continuous mode, step size $=0.01^{\circ}$ and step time $=0.5$ s over the $2 \theta$ angular range of $15-90^{\circ}$.

\subsubsection{NMR Spectroscopy}

${ }^{1} \mathrm{H}$ NMR, ${ }^{13} \mathrm{C}$ NMR, NOESY, HSQC and COSY spectra were obtained using a Bruker Avance $400 \mathrm{MHz}$ NMR spectrometer in $\mathrm{CDCl}_{3}$.

\subsubsection{Differential Scanning Calorimetry (DSC) and \\ Thermogravimetric Analysis (TG)}

DSC and TG experiments were carried out with a TA Instruments SDT Q600 V20.9 and Universal Analysis 2000 software (version 4.5A). A standard calibration process for the TG-DSC experiments was carried out with an empty pan, zinc $\left(T_{\text {fusion }}\right.$ : $419.5^{\circ} \mathrm{C}$ ) and sapphire standards to correct the baseline, temperature and heat flow, respectively. Accurately weighed samples in crimped aluminium pans were thermally scanned from $30^{\circ} \mathrm{C}$ to $900{ }^{\circ} \mathrm{C}$, heating at a rate of $10.0^{\circ} \mathrm{C} \mathrm{min}^{-1}$. A dry nitrogen purge was maintained at $10 \mathrm{~mL} \mathrm{~min}^{-1}$. The experiment was repeated by purging air at $10,15,20,25 \mathrm{~mL} \mathrm{~min}^{-1}$ to examine aerial oxidation with respect to temperature. Before testing, the instrument calibration was checked using a sample of calcium oxalate monohydrate according to ASTM norms.

\subsubsection{IR (ATR) Spectroscopy and Mass Spectrometry}

The Fourier transformed infrared spectra were recorded via attenuated total reflectance (ATR) using a Perkin Elmer Universal spectrometer. A Waters Micromass LCT Premier TOF-MS was used to attain the mass spectrum.

\section{Results and Discussion}

\subsection{Single Crystal Structure Analysis and Hirshfeld Surface Analysis}

The single crystal X-ray study of lumefantrine was carried out using crystals grown in a mixture of solvents. The crystal data are summarized in Table 1.

The Olex view of the lumefantrine molecule, presented in Fig. 1A, indicates that the fluorene rings are in the same plane and a little tilted on both ends. In Fig. 1B, the asymmetric unit of lumefantrine shows inter- as well as intramolecular $\mathrm{C}-\mathrm{H}$...Cl interactions, also molecular intra hydrogen bonding $\mathrm{O}-\mathrm{H}$...N interaction and $\mathrm{C}-\mathrm{H}$...O weak interactions. Due to the alternate
Table 1 Crystal data of lumefantrine.

\begin{tabular}{|c|c|}
\hline Parameters & Lumefantrine \\
\hline Formula & $\mathrm{C}_{30} \mathrm{H}_{32} \mathrm{Cl}_{3} \mathrm{NO}$ \\
\hline Mol. mass & 528.92 \\
\hline Temperature/K & 173 \\
\hline Radiation $(\AA)$ MoKa & 0.71073 \\
\hline Crystal system & Monoclinic \\
\hline Space group & $\mathrm{P}_{21}$ \\
\hline $\mathrm{a} / \AA$ & $8.8019(6)$ \\
\hline $\mathrm{b} / \AA ̊ \AA$ & $9.4406(6)$ \\
\hline$c / \AA ̊$ & $15.8201(11)$ \\
\hline$\alpha /^{\circ}$ & 90 \\
\hline$\beta /^{\circ}$ & $95.497(2)$ \\
\hline$\gamma /{ }^{\circ}$ & 90 \\
\hline Volume $/ \AA^{3}$ & $1308.53(15)$ \\
\hline Z & 2 \\
\hline Calculated density $/ \mathrm{g} \mathrm{cm}^{-3}$ & 1.342 \\
\hline $\left.\mathrm{Mu}(\mathrm{MoKa}) / \mathrm{mm}^{-1}\right)$ & 0.375 \\
\hline $\mathrm{F}(000)$ & 556 \\
\hline Crystal size $/ \mathrm{mm}^{3}$ & $0.09 \times 0.17 \times 0.20$ \\
\hline$\theta$ Min-Max $/^{\circ}$ & $2.3,28.3$ \\
\hline Dataset & $-11: 11 ;-12: 12 ;-14: 21$ \\
\hline Tot., uniq. data, $R_{\text {int }}$ & $11590,6499,0.023$ \\
\hline Observed data $[\mathrm{I}>2.0 \sigma(\mathrm{I})]$ & 5731 \\
\hline Nref, Npar & 6499,322 \\
\hline $\mathrm{R}, \mathrm{wR} 2, \mathrm{~S}$ & $0.0374,0.0860,1.03$ \\
\hline Min. and max. resd. dens./e $\AA^{-3}$ & $-0.20,0.27$ \\
\hline No. of $C-X \ldots \pi$ interactions & 2 \\
\hline No. of $\pi \ldots \pi$ interactions & 18 \\
\hline
\end{tabular}

$\mathrm{C}-\mathrm{H}$...Cl interactions, the molecules expand the lattice through the $b$ as well as $c$ axes, in the $a$-axis it makes chains, whilst in the $b$-axis it makes networks. There are in total $18 \pi \ldots \pi$ interactions, which cause a zigzag ladder-like structure in the $c$-axis. The hydrogen bonding and weak interactions of lumefantrine are listed in Table 2.

Hirshfeld surfaces, examining fingerprint plots, were created by CrystalExplorer 2.1 software which can recognize the types and regions of the intermolecular interactions, and the proportion of this interaction. The molecular Hirshfeld surface in the crystal structure is accumulated from the electron distribution. Hirshfeld surfaces of the compound have been mapped over $d_{\text {norm }}$ and electrostatic potential (Fig. 2). The normalized contact distance $\left(d_{\text {norm }}\right)$ is based on both $d_{e^{\prime}} d_{i}$ and the van der Waals
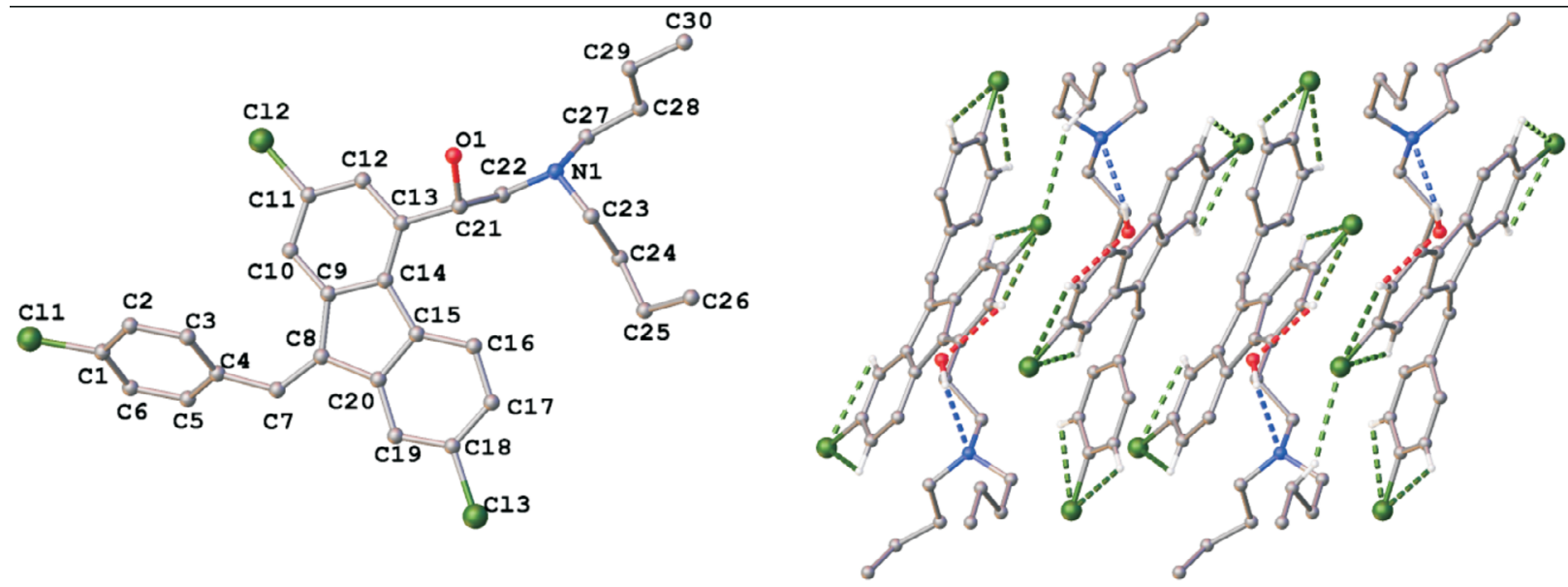
Table 2 Hydrogen bonding and weak interactions of lumefantrine.

\begin{tabular}{llllll}
\hline Donor-H...Acceptor & D-H & H...A & D ...A & D-H...A & Bonding \\
\hline $\mathrm{O}(1)-\mathrm{H}(1) \ldots \mathrm{N}(1)$ & $0.96(3)$ & $2.20(2)$ & $2.767(2)$ & $116(2)$ & H-bonding \\
$\mathrm{C}(22)-\mathrm{H}(22 \mathrm{~B}) \ldots \mathrm{Cg}(2)^{\mathrm{a}}$ & 0.768 & 2.95 & $3.718(2)$ & 135 & $\mathrm{C}-\mathrm{H} \ldots \mathrm{Cg}$ \\
$\mathrm{C}(11)-\mathrm{Cl}(2) \ldots \mathrm{Cg}(1)^{\mathrm{b}}$ & 1.102 & $3.5919(10)$ & $4.694(2)$ & $119.07(7)$ & $\mathrm{C}-\mathrm{Cl} \ldots \mathrm{Cg}$ \\
\hline
\end{tabular}

a Symmetry transformations used to generate equivalent atoms: $1-X, 1 / 2+Y,-Z ;{ }^{b} 1-X, 1 / 2+Y,-Z$.

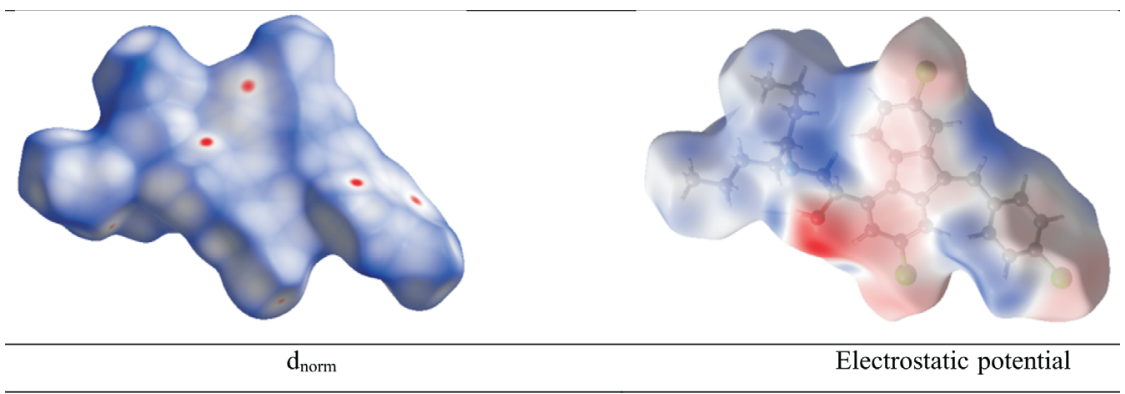

Figure $2 d_{\text {norm }}$ and electrostatic potential of lumefantrine.

$(\mathrm{vdw})$ radii of the atom, as listed in Equation 1. The 2D fingerprint plot is the combination of $d e$ and $d_{i}$, where $d_{e}$ is the distance from the point to the nearest nucleus external to the surface, while $d_{i}$ is the distance to the nearest nucleus internal to the surface. The value of $d_{\text {norm }}$ is negative or positive when intermolecular contacts are shorter or longer than the van der Waals separations, respectively. The interactions between the functional groups are shown as deep red areas in the Hirshfeld surfaces. Slight red areas on the surface correspond to weaker and longer contacts than the hydrogen bonds. Visible spots are attributed to the $\mathrm{H} \cdots \mathrm{H}$ contacts. The normalized distance $\left(d_{\text {norm }}\right)$, based on $d_{\mathrm{e}}$ and $d_{\mathrm{i}}$, is given by Equation 1 .

$$
d_{\text {norm }}=\left(d_{\mathrm{i}}-r_{\mathrm{i}}^{\mathrm{vdw}}\right) / r_{\mathrm{i}}^{\mathrm{vdw}}+\left(d_{\mathrm{e}}-r_{\mathrm{e}}^{\mathrm{vdw}}\right) / r_{\mathrm{e}}^{\mathrm{vdw}}
$$

where $r_{\mathrm{i}}^{\mathrm{vdw}}$ and $r_{\mathrm{e}}^{\mathrm{vdw}}$ are the van der Waals (vdw) radii of the atoms.

The result obtained from the Hirshfeld surface of lumefantrine is shown in Fig. 3. The inter- and intramolecular $\mathrm{H} \cdots \mathrm{O} / \mathrm{O} \cdots \mathrm{H}$ interactions between $\mathrm{C}-\mathrm{H}$ and the hydroxyl group oxygen with a $2.6 \%$ proportion appear as short spikes in the $2 \mathrm{D}$ fingerprint plot. The $2.8 \% \mathrm{C} \cdots \mathrm{Cl}$ contribution between carbon and chlorine appears as a scissor wing in the centre. $\mathrm{C}-\mathrm{H} . . . \pi$ interactions are present because the two-dimensional fingerprint plot shows two pairs of typical 'wings' at the top left and bottom right.

The wings at the bottom right $\left(d_{e}>d_{\mathrm{i}}\right)$ correspond to the surface around the acceptor, whereas those at the top left $\left(d_{\mathrm{i}}<d_{\mathrm{e}}\right)$ are due to points on the surface around the $\mathrm{C}-\mathrm{H}$ donor. Herein, for all $\mathrm{C}-\mathrm{H}$...C interactions, $\mathrm{C}-\mathrm{H} \ldots \pi$ appear in the fingerprint plot as a characteristic style of C...C bond contacts, comprising $3.3 \%$. C...H/H...C contacts make up $20.0 \%$ of the total Hirshfeld surface area. The inter- and intramolecular $\mathrm{C}-\mathrm{H} \ldots \mathrm{Cl}$ interactions between $\mathrm{C}-\mathrm{H}$ and chlorine, with a $25.9 \%$ proportion, is seen as short spikes in the $2 \mathrm{D}$ fingerprint plot.

\subsection{Powder X-ray Diffraction}

The powder X-ray diffraction pattern of lumefantrine is shown in Fig. 4. The compound shows a wide range of reflections ranging from $2 \theta=10^{\circ}-50^{\circ}$. The compound shows a pattern that corresponds to a single crystalline phase. The peaks are sharp, which shows the crystalline nature of the molecule. The powder $X$-ray pattern matches the single crystal powder patterns. The resultant lattice parameters are summarized in Table 3.

\subsection{NMR Spectroscopy}

Examination of the ${ }^{1} \mathrm{H}-\mathrm{NMR}$ spectrum of lumefantrine (Fig. 5) confirmed the presence of the hydroxyl group at $4.51 \mathrm{ppm}$ as a singlet, which corresponds to one proton. The H21 proton appears as a $d d$ at 5.35 , which corresponds to one proton. The four $\mathrm{N}-\mathrm{CH}_{2}$ protons appear at $2.47-2.72 \mathrm{ppm}$ as a multiplet. The $\mathrm{CH}_{2}$ protons of carbons 25,28 and 26,29 give signals between $1.33-1.40$ and $1.45-1.51 \mathrm{ppm}$, respectively. Each signal is seen as a multiplet and corresponds to four protons. The $\mathrm{CH}_{3}$ protons appear at 0.96 as a triplet corresponding to six protons.

${ }^{13} \mathrm{C}$ DEPT, COSY, NOESY and HSQC was used to confirm assignment of protons. The 2D NMR spectra (ESI), assignments

Table 3 The lattice parameters from powder and single crystal XRD.

\begin{tabular}{|c|c|c|c|c|}
\hline $2 \theta$ & $\mathrm{d} / \mathrm{A}$ & $\mathrm{h}$ & $\mathrm{k}$ & 1 \\
\hline 11.37 & 7.78 & 0 & 0 & 2 \\
\hline 13.74 & 6.44 & 1 & 1 & 0 \\
\hline 14.52 & 6.10 & 0 & 1 & 2 \\
\hline 15.32 & 5.78 & 1 & 1 & 1 \\
\hline 16.31 & 5.44 & 1 & 0 & 2 \\
\hline 17.14 & 5.17 & 1 & 1 & -2 \\
\hline 18.32 & 4.84 & 1 & 1 & 2 \\
\hline 20.25 & 4.39 & 2 & 0 & 0 \\
\hline 20.44 & 4.35 & 2 & 0 & -1 \\
\hline 21.28 & 4.18 & 2 & 1 & 0 \\
\hline 22.33 & 3.98 & 2 & 1 & 0 \\
\hline 23.32 & 3.82 & 2 & 1 & 1 \\
\hline 24.32 & 3.66 & 0 & 1 & 4 \\
\hline 25.80 & 3.45 & 2 & 1 & 2 \\
\hline 26.60 & 3.35 & 1 & 2 & -3 \\
\hline 27.52 & 3.24 & 1 & 1 & 4 \\
\hline 28.68 & 3.11 & 2 & 2 & 1 \\
\hline 29.46 & 3.03 & 2 & 1 & 3 \\
\hline 31.73 & 2.82 & 3 & 0 & 1 \\
\hline 33.24 & 2.70 & 0 & 3 & 3 \\
\hline 37.15 & 2.42 & 3 & 2 & 1 \\
\hline 39.66 & 2.27 & 1 & 2 & -6 \\
\hline 43.11 & 2.10 & 4 & 0 & -3 \\
\hline 44.50 & 2.04 & 2 & 1 & -7 \\
\hline 46.00 & 1.97 & 0 & 0 & 8 \\
\hline 49.70 & 1.83 & 3 & 1 & -7 \\
\hline
\end{tabular}




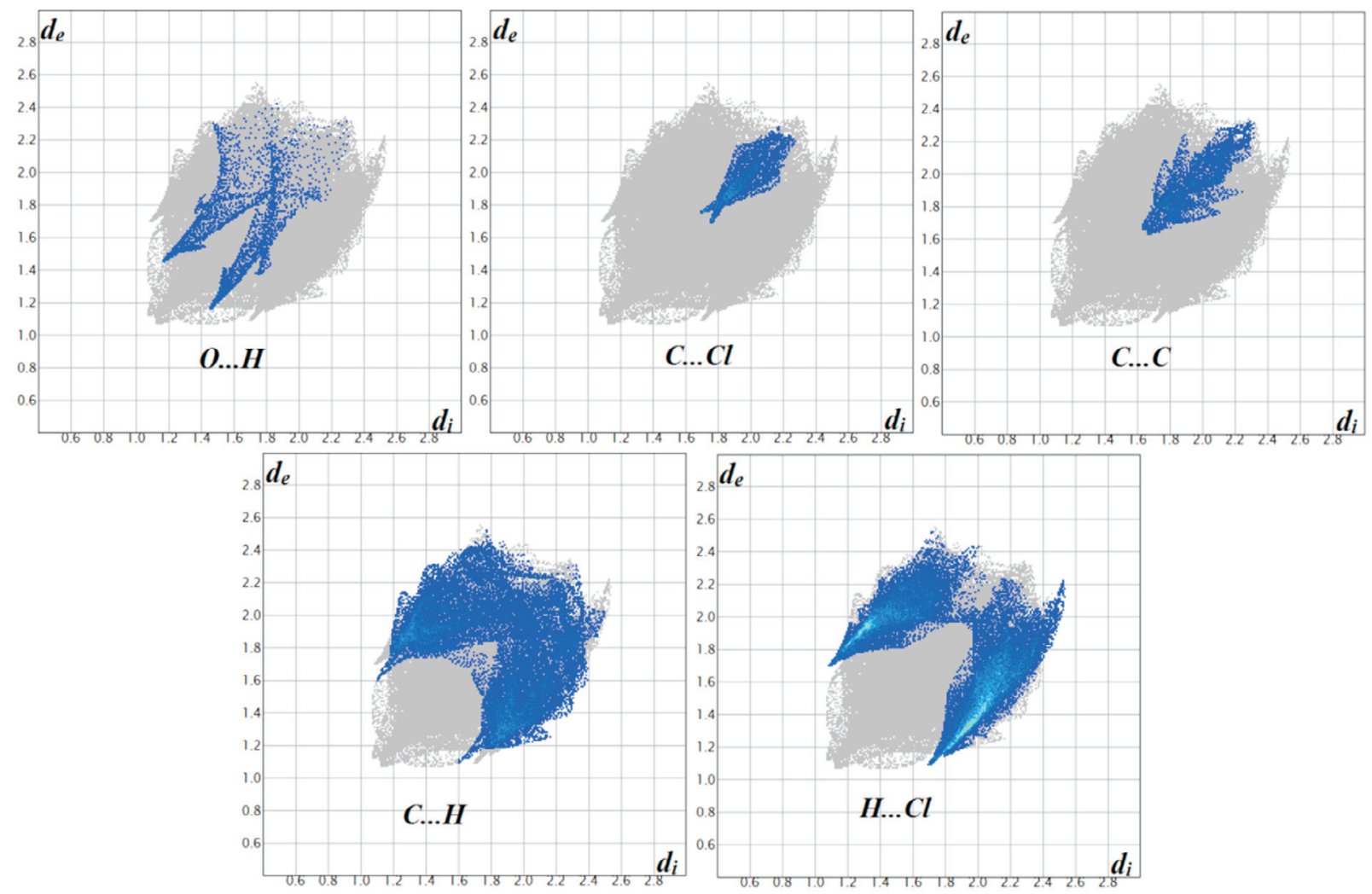

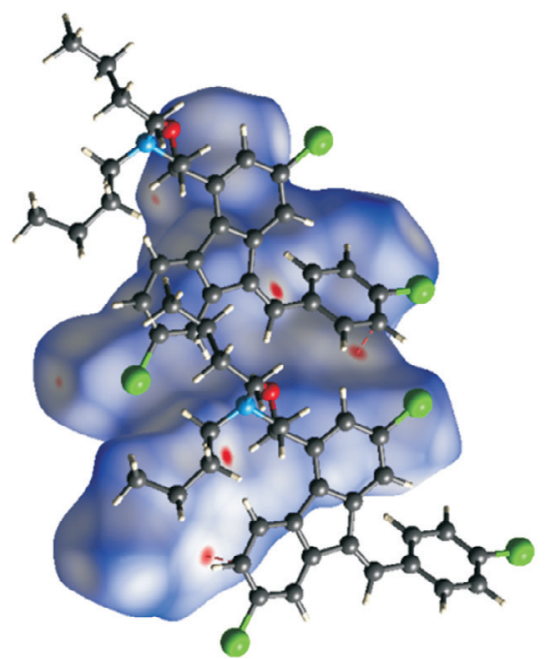

C...C contacts

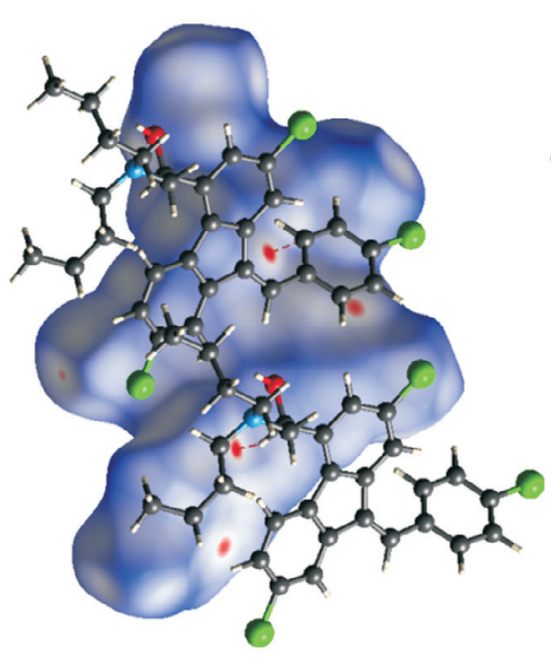

C...H contacts

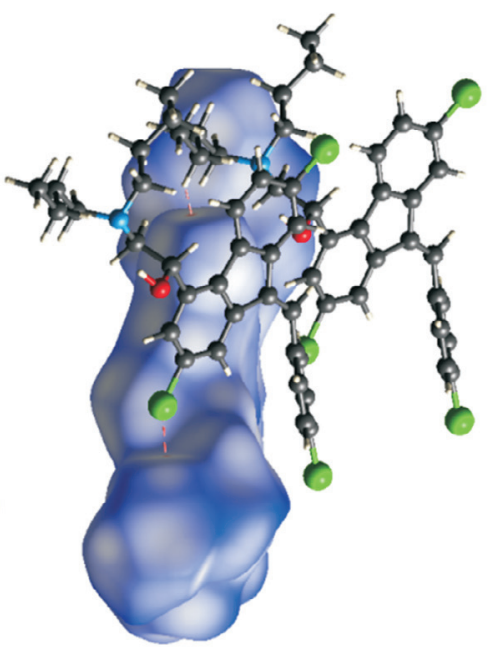

C...Cl contacts

Figure 3 Fingerprint plots of lumefantrine contacts, resolved into different intermolecular interactions contributing to the total Hirshfeld surface area of the molecules.

are given in Table 4. Thus protons H16, 17, 19, 20 are seen at 7.43-7.47 ppm as multiplets as correlated by COSY, whilst the aromatic protons $\mathrm{H} 16$ and 20 correlates to H14 via NOE. A relationship was seen between $\mathrm{H} 6, \mathrm{H} 12$ and H21. Further correlations were found between the dibutylamine ring protons $\mathrm{H} 12$ and the $\mathrm{N}$-methyl protons $\mathrm{H} 22$.

\subsection{Thermal Analysis}

The thermogravimetric (TG) analyses plots of the lumefantrine powder, that were obtained under air with different heating rates can be seen in Fig. 8. Table 5 shows the TG results for the decomposition of lumefantrine, and includes decomposition temperatures, mass loss, and peak temperatures of the DSC and TG analyses.
Lumefantrine did not show loss of water content up to $132{ }^{\circ} \mathrm{C}$ (its melting temperature) in the TG traces in Fig. 6. It is confirmed that its decomposition does not occur directly after its melting. One can easily observe in the inert environment, decomposition after the melting point in a first step, giving a $16.1 \%$ mass loss, followed by a $16.9 \%$ loss. The third step loss of $23.7 \%$ leaves behind $29.1 \%$ mass. In the case of decomposition in air, the first step gives a $42.1 \%$ loss, followed by a $51.0 \%$ loss, leaving behind only $6.4 \%$.

The thermogravimetric analyses results are expressed as a function of conversion $\alpha$, which is defined in Equation $2 .{ }^{13}$ The mass loss phenomenon is closely related to the nature of the compound (Fig. 7), because thermal decomposition is directly related to the stability of the compound. 
Table $4{ }^{1} \mathrm{H}-\mathrm{NMR},{ }^{13} \mathrm{C}-\mathrm{NMR}$ and 2D NMR assignment of lumefantrine.

\begin{tabular}{|c|c|c|c|c|c|c|}
\hline Carbon & ${ }^{13} \mathrm{C}$ NMR & Proton & ${ }^{1} \mathrm{H} \mathrm{NMR}$ & COSY & NOESY & HSQC \\
\hline 1 & 130.7 & $\mathrm{H} 1$ & $7.44(\mathrm{H}, \mathrm{m}, 7.43-7.47)$ & - & - & $\mathrm{H} 1$ \\
\hline 2 & 134.3 & - & - & - & - & - \\
\hline 3 & 126.5 & $\mathrm{H} 6$ & $7.67(\mathrm{H}, \mathrm{m}, 7.67-7.67)$ & - & $\mathrm{H} 21$ & - \\
\hline 4 & 138.4 & - & - & - & - & - \\
\hline 5 & 136.6 & - & - & - & - & - \\
\hline 6 & 120.8 & $\mathrm{H} 3$ & $7.71(\mathrm{H}, \mathrm{m}, 7.71-7.72)$ & - & - & - \\
\hline 7 & 135.1 & - & - & - & - & - \\
\hline 8 & 140.0 & - & - & - & - & - \\
\hline 9 & 133.0 & - & - & - & - & - \\
\hline 10 & 127.8 & H10 & $7.58(\mathrm{H}, \mathrm{m}, 7.56-7.60)$ & - & - & - \\
\hline 11 & 133.3 & - & - & - & - & - \\
\hline 12 & 124.1 & $\mathrm{H} 12$ & $7.58(\mathrm{H}, \mathrm{m}, 7.56-7.60)$ & - & $\mathrm{H} 21$ & - \\
\hline 13 & 141.7 & - & - & - & - & - \\
\hline 14 & 128.5 & H14 & $7.31(\mathrm{H}, \mathrm{m}, 7.30-7.32)$ & - & H16, 20 & - \\
\hline 15 & 135.1 & - & & - & - & - \\
\hline 16,20 & 130.7 & H16, 20 & $7.44(2 \mathrm{H}, \mathrm{m}, 7.43-7.47)$ & H17, 19 & H14 & - \\
\hline 17,19 & 129.2 & $\mathrm{H} 17,19$ & $7.44(2 \mathrm{H}, \mathrm{m}, 7.43-7.47)$ & $\mathrm{H} 16,20$ & $\mathrm{H} 14$ & - \\
\hline 18 & 134.8 & - & - & - & - & - \\
\hline 21 & 65.6 & $\mathrm{H} 21$ & $5.35(\mathrm{H}, \mathrm{dd}, \mathrm{J}=4.3)$ & $\mathrm{H} 22$ & $\mathrm{H} 6,12$ & $\mathrm{H} 21$ \\
\hline 22 & 60.1 & $\mathrm{H} 22$, & $\begin{array}{l}2.44(\mathrm{H}, \mathrm{m}, 2.41-2.44) \\
2.87(\mathrm{H}, \mathrm{m}, 2.85-2.89)\end{array}$ & $\mathrm{H} 21$ & $\mathrm{H} 23,24$ & $\mathrm{H} 22$ \\
\hline 23,24 & 53.5 & $\mathrm{H} 23,24$ & $2.59(4 \mathrm{H}, \mathrm{m}, 2.47-2.72)$ & $\mathrm{H} 25,28$ & $\mathrm{H} 22,26,29$ & $\mathrm{H} 23,24$ \\
\hline 25,28 & 29.2 & $\mathrm{H} 25,28$ & $1.49(4 \mathrm{H}, \mathrm{m}, 1.45-1.51)$ & $\mathrm{H} 23,24,26,29$ & $\mathrm{H} 27,30$ & $\mathrm{H} 25,28$ \\
\hline 26,29 & 20.7 & $\mathrm{H} 26,29$ & $1.36(4 \mathrm{H}, \mathrm{m}, 1.33-1.40)$ & $\mathrm{H} 27,30,25,28$ & $\mathrm{H} 23,24$ & $\mathrm{H} 26,29$ \\
\hline 27,30 & 14.2 & $\mathrm{H} 27,30$ & $0.96(6 \mathrm{H}, \mathrm{t}, \mathrm{J}=7.2)$ & $\mathrm{H} 26,29$ & $\mathrm{H} 25,28$ & $\mathrm{H} 27,30$ \\
\hline
\end{tabular}

$$
\alpha=\frac{M_{0}-M}{M_{0}-M_{\infty}}
$$

where $M$ is the actual mass of sample; $M_{0}$ is the initial mass of sample and $M_{\infty}$ is the final mass of the sample.

The TG curves show a two-step decomposition pattern. As the heating rate increased, the onset temperature of the DTG curves and the peak temperature increased. These temperature shifts may be due to heat transfer. This might be due to rapid pyrolysis, which requires very high rates of heating and short residence times of reactant and products. The activation energies for thermal degradation were determined according to the Flynn and Wall and Ozawa (FWO) and Kissinger-Akahira-Sunose (KAS) methods. ${ }^{14-19}$

The rate of degradation of sample, $d \alpha / d t$, depends on the mass

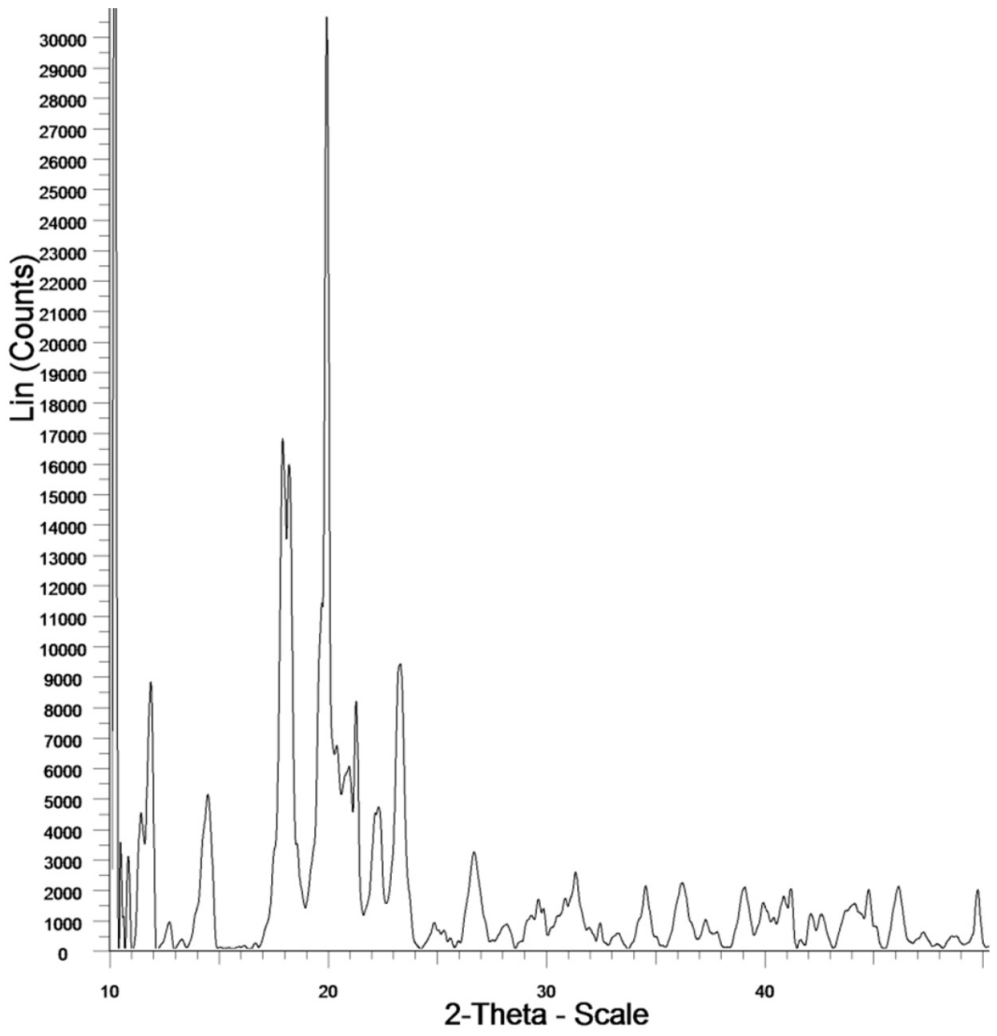

Figure 4 Powder X-ray pattern of lumefantrine. 


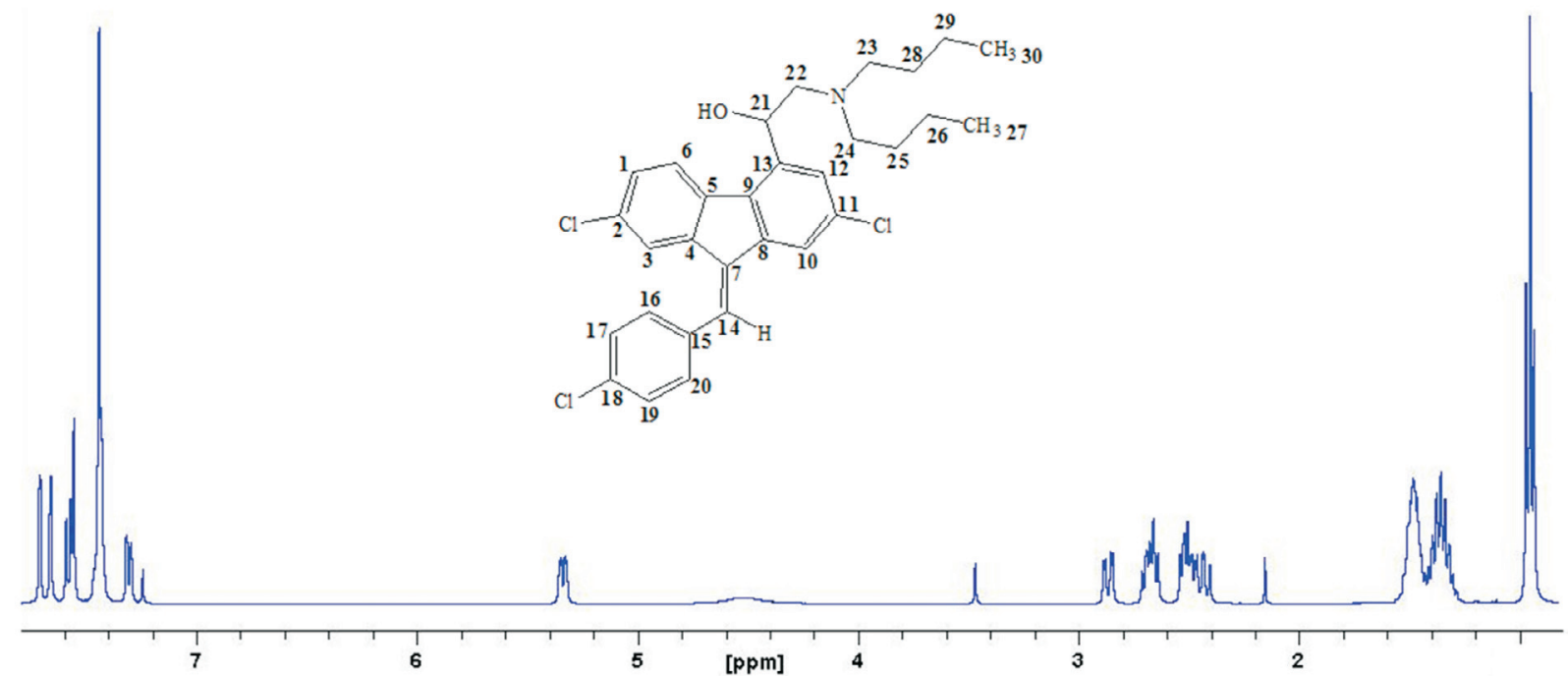

Figure $5{ }^{1} \mathrm{H}$ NMR spectrum of lumefantrine.

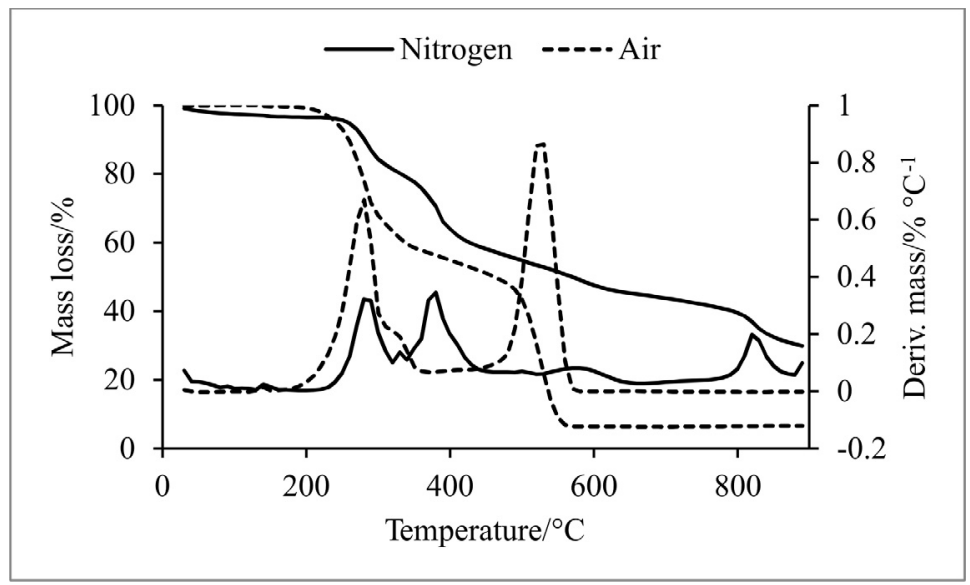

Figure 6 TG-DTG of lumefantrine in nitrogen.

of sample and temperature. This is expressed as shown in Equation 3:

$$
\frac{d \alpha}{d t}=k f(\alpha)
$$

where $\mathrm{k}$ is the rate constant and $f(\alpha)$ is the conversion functional relationship, and $f(\alpha)$ is the proportional to the decomposition of non-degraded or un-reacted material.

The temperature dependence of the rate constant $k$ may be described by the Arrhenius expression (Equation 4):

$$
k=A \exp \left(\frac{E_{a}}{R T}\right)
$$

Combining equations (3) and (4) gives the overall rate of loss of reactive materials as:

$$
\frac{d \alpha}{d t}=A f(\alpha) \exp \left(-\frac{E_{a}}{R T}\right)
$$

The Flynn and Wall and Ozawa (FWO) method determines activation energy from the temperature versus mass loss data obtained at different heating rates, Equation 6:

$$
\ln \beta=\left[\ln \frac{A E_{a}}{R}-\log (g(\alpha))-5.33\right]-1.052 \ln \left(\frac{E_{a}}{R T}\right)
$$

where $\beta$ is the heating rate.

Should the degradation process mechanism be independent of the heating rate, then at constant $\alpha, \mathrm{g}(\alpha)$ is constant. Then the activation energy $\left(E_{a}\right)$ is obtained from the slope of the linear equation, by plotting $\ln \beta$ against $1000 / \mathrm{T}$ at a particular conversion. Fig. 8 shows the FWO plot of degradation of lumefantrine.

The Kissinger-Akahira-Sunose (KAS) method is an isoconver-

\begin{tabular}{|c|c|c|c|c|c|c|c|c|}
\hline \multirow{3}{*}{$\begin{array}{l}\text { Heating rate } \\
{ }^{\circ} \mathrm{C} \mathrm{min}^{-1}\end{array}$} & \multicolumn{4}{|c|}{ TG-DTG } & \multirow{3}{*}{$\underset{\%}{\text { Residue }}$} & \multicolumn{3}{|c|}{ DSC } \\
\hline & \multicolumn{2}{|c|}{ Stage 1} & \multicolumn{2}{|c|}{ Stage 2} & & \multirow{2}{*}{$\begin{array}{l}\mathrm{mp} \\
\mathrm{T}_{\mathrm{m}}\end{array}$} & \multirow{2}{*}{$\begin{array}{c}\text { Stage } 1 \\
\mathrm{~T}_{\mathrm{p}}\end{array}$} & \multirow{2}{*}{$\begin{array}{c}\text { Stage } 2 \\
\mathrm{~T}_{\mathrm{p}}\end{array}$} \\
\hline & $\mathrm{T}_{\mathrm{p}}$ & $\%$ loss & $\mathrm{T}_{\mathrm{p}}$ & $\%$ loss & & & & \\
\hline 10 & 317.4 & 56.5 & 575.1 & 38.4 & 1.8 & 136.8 & 337.6 & 585.4 \\
\hline 15 & 329.4 & 49.2 & 636.2 & 21.9 & 1.9 & 138.8 & 347.6 & 626.2 \\
\hline 20 & 335.4 & 46.0 & 638.9 & 31.8 & 2.9 & 140.0 & 353.3 & 630.6 \\
\hline 25 & 339.0 & 55.0 & 641.0 & 24.0 & 2.5 & 141.8 & 360.3 & 686.8 \\
\hline
\end{tabular}
sion method and the activation energy can be calculated via Equation 7, to give Fig. 9.

Table 5 Thermo analytical data of lumefantrine at different heating rates under air. 


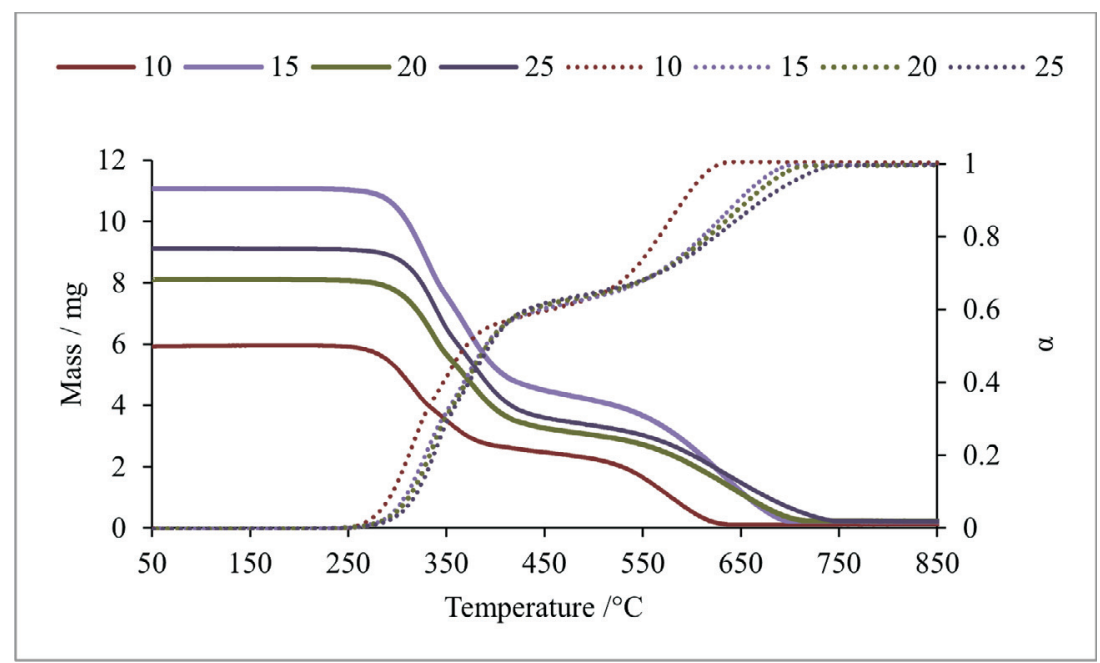

Figure 7 TG and conversion- $\alpha$ curve of lumefantrine in air at different heating rates.

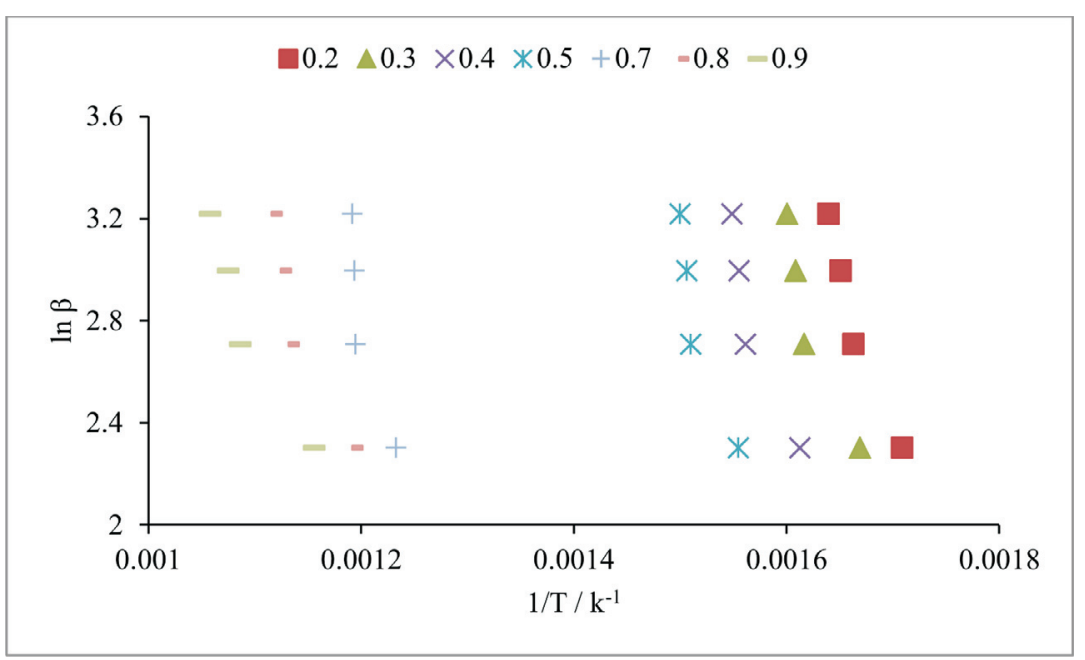

Figure 8 FWO plot for decomposition of lumefantrine.

$$
\ln \left(\frac{\beta}{T^{2}}\right)=\left(\ln \frac{A R}{g(\alpha) E}\right)-\frac{E_{a}}{R T}
$$

The activation energies determined via the FWO and KAS methods are given in Table 6 . The results for stage 1 decomposition are fairly compatible with each other, whilst those for stage 2 are less so. Both the methods are isoconversion methods by integral equations and show the same trends. The activation energy values from the KAS method are somewhat lower than the values from the FWO method. This may be because the KAS method is more valid for conversion- $\alpha$ value $20 \leq \alpha \leq 50$, which is only applicable for the step 1 degradation here.

The DSC curves under nitrogen as well as in air for lumefantrine are shown in Fig. 10. Small peaks represent endo $\left(49.1^{\circ} \mathrm{C}\right)$ endo $\left(132.2^{\circ} \mathrm{C}\right)$-exo $\left(196.5^{\circ} \mathrm{C}\right)$-endo $\left(257.6^{\circ} \mathrm{C}\right)$ events under nitrogen, whilst the $\operatorname{exo}\left(51.6^{\circ} \mathrm{C}\right)$-endo $\left(134.7^{\circ} \mathrm{C}\right)$-exo $\left(293.5^{\circ} \mathrm{C}\right)$ endo $\left(459.2^{\circ} \mathrm{C}\right)$ in air is quite different and is associated with the crystallinity of the compound. The DSC trace endo peak

Table 6 Calculated activation energies from the FWO and KAS. $\left(459.2^{\circ} \mathrm{C}\right)$, followed by an exo peak $\left(522.4^{\circ} \mathrm{C}\right)$ of the lumefantrine confirmed the complete decomposition process in air. Since the exo peak at $522.4^{\circ} \mathrm{C}$ in air shows a high temperature degradation pattern that is different than what occurred under nitrogen; we can assume reactive species in the latter case may react with oxygen from air. These calorimetric results support the PXRD data confirming that lumefantrine is crystalline.

Figure 11a shows the DSC curves of lumefantrine and the corresponding DSC data are tabulated in Table 5. Fig. 11a shows that the peak associated with thermal decomposition moves up with increasing heating rate. The DSC curves in Fig. 11b show endo-exo-endo behaviour in the approximate temperature range of $250-450{ }^{\circ} \mathrm{C}$ between the two forms.

This is because lumefantrine undergoes the first degradation step with multiple polymorphic forms, which have different melting points. These could undergo reversible solid to solid transitions. Should the temperature reach the crystalline trans-

\begin{tabular}{|c|c|c|c|c|c|c|c|c|c|}
\hline \multirow{3}{*}{ Compounds } & \multicolumn{9}{|c|}{ Conversion $\alpha$} \\
\hline & 0.2 & 0.3 & 0.4 & 0.5 & Average $\mathrm{kJ} \mathrm{mol}^{-1}$ & 0.7 & 0.8 & 0.9 & Average $\mathrm{kJ} \mathrm{mol}^{-1}$ \\
\hline & \multicolumn{5}{|c|}{ Stage 1} & \multicolumn{4}{|c|}{ Stage 2} \\
\hline FWO & 99.9 & 95.1 & 99.6 & 114.9 & 102.4 & 139.0 & 84.6 & 69.6 & 97.7 \\
\hline KAS & 86.8 & 81.7 & 86.3 & 135.0 & 97.4 & 125.7 & 67.9 & 51.7 & 81.8 \\
\hline
\end{tabular}




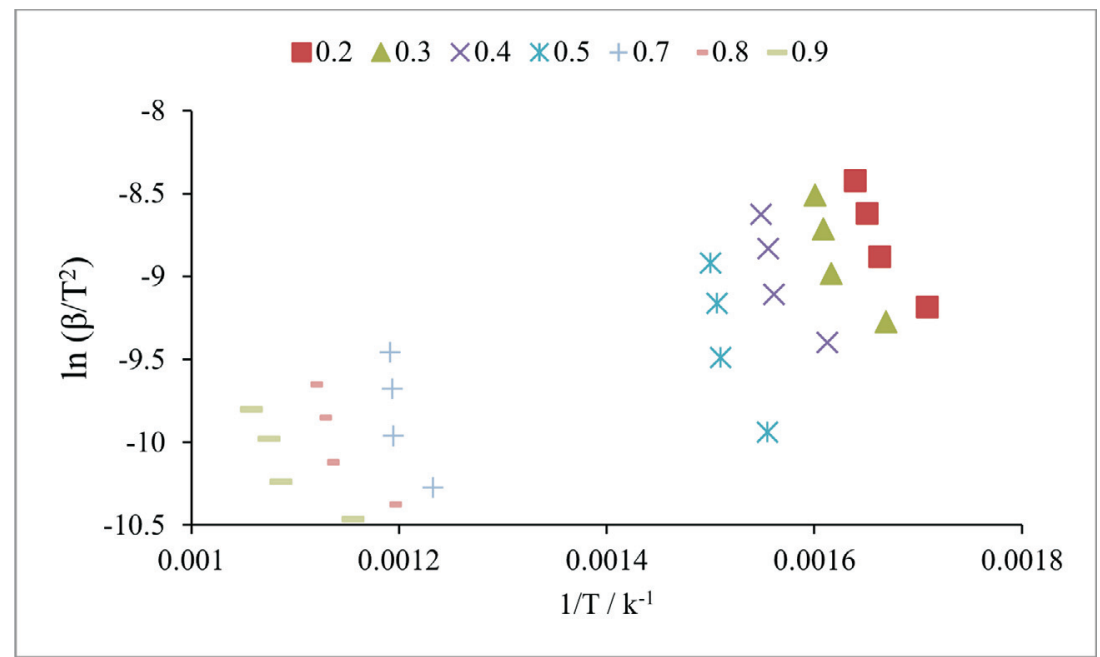

Figure 9 KAS plot for decomposition of lumefantrine.

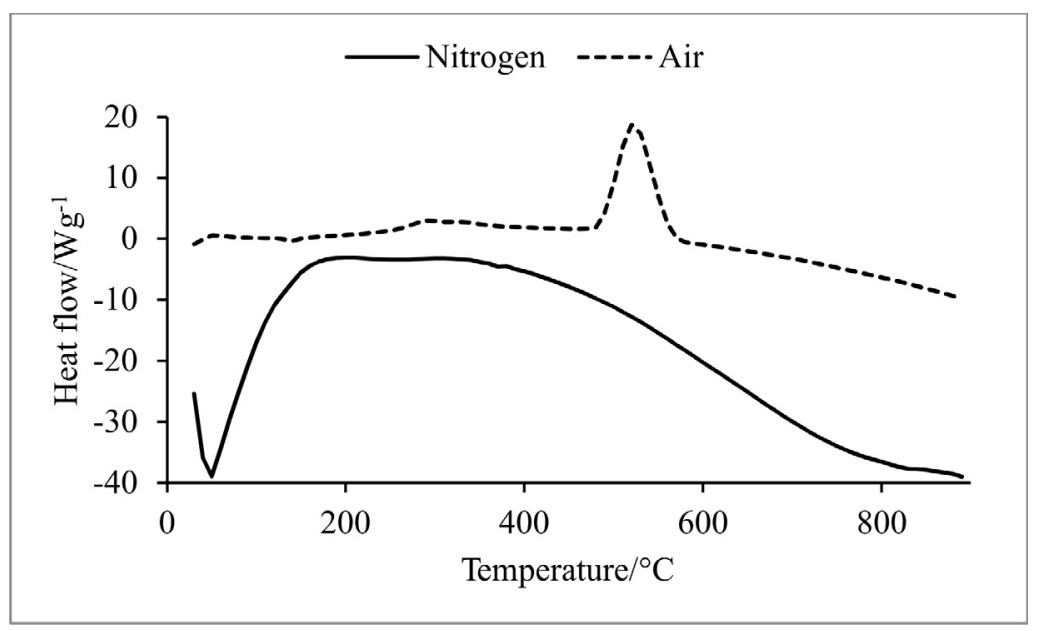

Figure 10 DSC of lumefantrine in nitrogen.

formation temperature under linear heating conditions, the one polymorph could be transformed to another polymorph. This polymorph transformation process produces exothermic/endothermic effects.

The activation energy variation also supports the results obtained from DSC. There is a solid to solid transition in the stage 1 decomposition adduct which has lower activation energy lower than that of observed in the stage 2 decomposition. The activation energy values for $\alpha$ : 0.7, 0.8, and 0.9 vary, and from the DSC data it is seen that there are transformations of polymorphs in the decomposition process.

The exothermic peak due to crystalline transformation is very weak and easily masked by the endothermic peak due to melting at a rapid heating rate. Hence, there is only one clear endo-

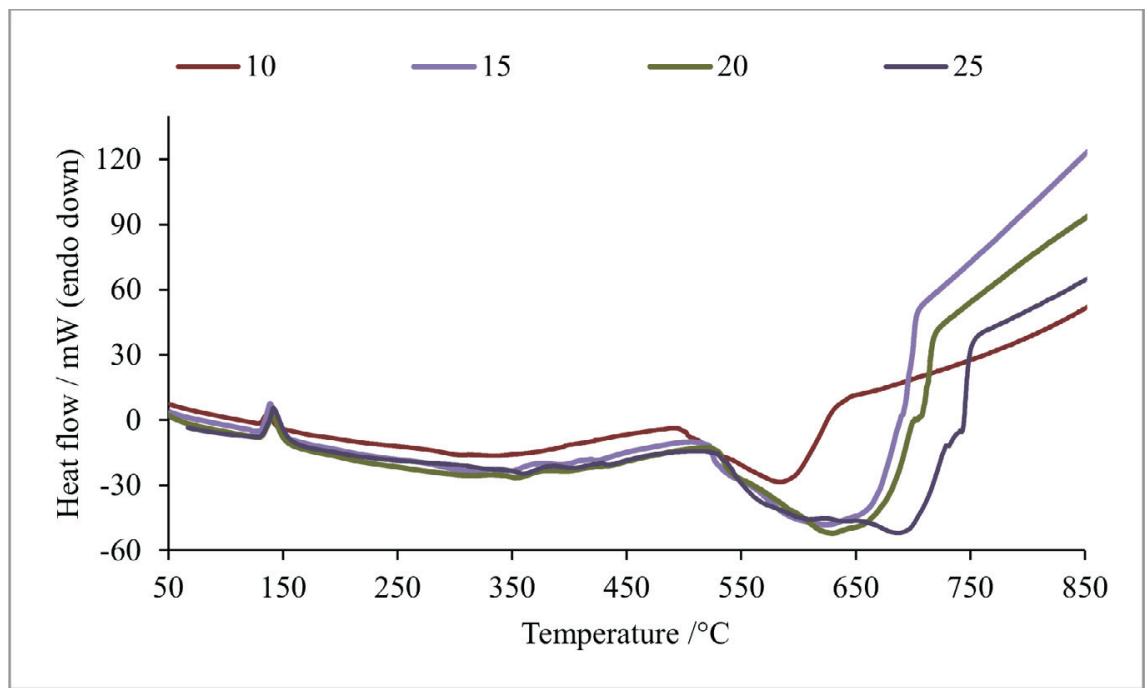

Figure 11a DSC of lumefantrine in air at different heating rates. 


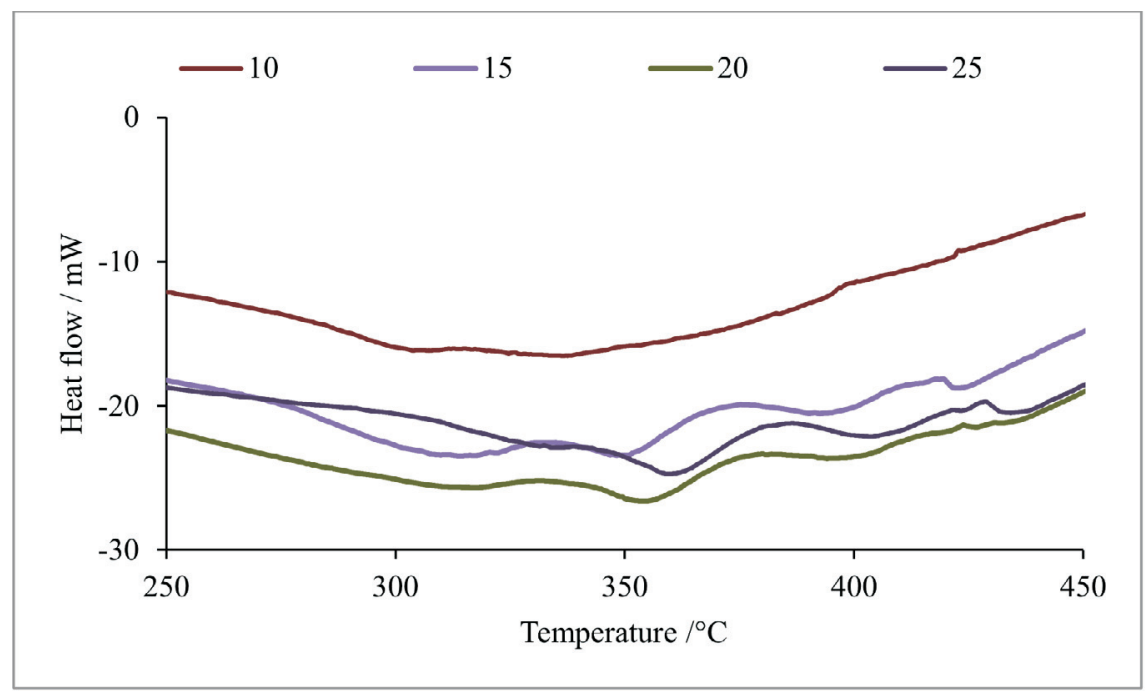

Figure 11b DSC of lumefantrine in air at different heating rates.

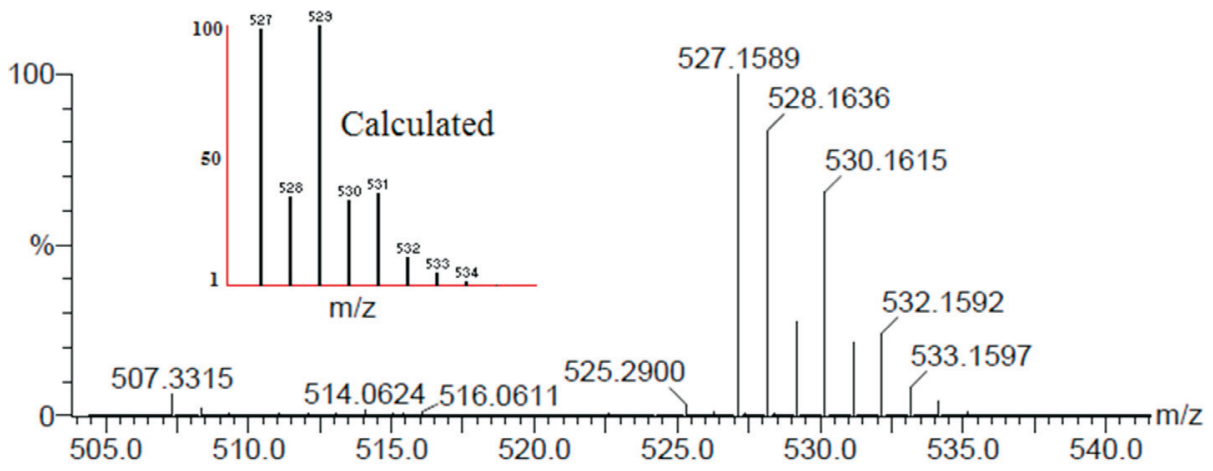

Figure 12 HRMS of lumefantrine.

thermic peak in the curve at $10{ }^{\circ} \mathrm{C} \mathrm{min}^{-1}$. A small shoulder precedes the second step decomposition endothermic on the $15-25{ }^{\circ} \mathrm{C} \min ^{-1}$ curve, while there is no shoulder peak on the $10{ }^{\circ} \mathrm{C} \mathrm{min}^{-1}$ curve, probably due to the thermal decomposition mechanism and heating rate.

\subsection{IR Spectroscopy (ATR) and Mass Spectrometry}

In the FTIR spectra, characteristic bands are seen at 3392.2, $2950.2,2927.0,2870.0,1863.88,1752.32,1634.3,1588.45,1485.6$, $1463.5,1442.5,1397.0,1365.3,1339.9,1307.7,1267.5,1172.7$, 1155.6, 1097.7, 1087.5, 1069.9, 1013.5, 932.8, 872.6, 839.3, 805.2, $769.6,752.1,696.1,654.9,559.8,521.5 \mathrm{~cm}^{-1}$.

Thus, the IR spectrum of pure lumefantrine showed characteristic sharp peaks of alkane stretching/bending $\left(-\mathrm{CH}_{3},-\mathrm{CH}_{2}\right.$ and -CH) vibrations at $\sim 1365.3, \sim 1485.6, \sim 2870.0$ and $\sim 2927.0 \mathrm{~cm}^{-1}$. It also exhibited a C-O stretch at $\sim 1172.7 \mathrm{~cm}^{-1}$ and a peak due to saturated hydroxyl $\mathrm{O}-\mathrm{H}$ bending at $\sim 3392.2 \mathrm{~cm}^{-1}$. A selective stretching vibration at $\sim 1155.6 \mathrm{~cm}^{-1}$ for the tertiary amine was also observed. Most of the peaks observed in the spectral region $769-872 \mathrm{~cm}^{-1}, 559-696 \mathrm{~cm}^{-1}$, and $839-1013 \mathrm{~cm}^{-1}$ are due to bending of $\mathrm{C}-\mathrm{H}$, as well as $-\mathrm{CH}_{2}$ and $-\mathrm{CH}$ deformation.

The mass spectrum of lumefantrine (Fig. 12) shows prominent $\mathrm{m} / \mathrm{z}$ peaks of $\mathrm{M}-1$ : $527.15, \mathrm{M}: 528.16, \mathrm{M}+2: 530.16$ and $\mathrm{M}+4$ : $532.15 \mathrm{amu}$. The obtained mass spectrum is well matched with the calculated one (inset) and the profile shows the chlorine isotopes.

\section{Conclusion}

The structure of lumefantrine has been determined in solution and solid state using SCXRD, PXRD, NMR, DSC, TG and IR. The single crystal structure helped to understand the molecular interactions. PXRD patterns show that the drug has a single crystalline phase. The Hirshfeld surface analysis has helped to understand the contribution of intermolecular interactions on the surface of the molecular crystal. Thus using the SCXRD result, the maximum surface area of the molecule is occupied by $\mathrm{C}-\mathrm{H} . . . \mathrm{Cl}$ interactions. The thermal studies of the compound helped to confirm the melting process and thermal stability. Hence, TG shows a stepwise degradation process. It is concluded that aereal oxidative degradation of the drug may be low up to $325^{\circ} \mathrm{C}$, but at high temperature it decomposes rapidly. The results reported here may be useful for the development and modification of synthetic processes, new formulations and the further study of physicochemical properties of lumefantrine.

\section{Supplementary Material}

The supporting information contains the ${ }^{1} \mathrm{H} \mathrm{NMR},{ }^{13} \mathrm{C} \mathrm{NMR}$, NOESY, COSY, and HSQC spectra. CCDC-990132 contains the supplementary crystallographic data for this paper. These data can be obtained free of charge at www.ccdc.cam.ac.uk/conts/ retrievel.html or from the Cambridge Crystallographic Data Centre, 12 Union Road, Cambridge CB2 1EZ, UK; fax +44 1223/336 033; e-mail: deposit@ccdc.ac.uk

\section{Acknowledgements}

P.B.P. is thankful to the University of KwaZulu-Natal, Durban, South Africa, for a postdoctoral fellowship.

\section{SORCID iD}

H.B. Friedrich: (iD) orcid.org/0000-0002-1329-0815 


\section{References}

1 World Health Organization, 2011, http://www.who.int/malaria/publications/world_malaria_report_2012/report/en/index.html

2 J.D. Maguire, I.W. Sumawinata, S. Masbar, B. Laksana, P. Prodjodipuro, P. Sismadi, N. Mahmud, M.J. Bangs, J.K. Baird and I. Susanti, Chloroquine-resistant Plasmodium malariae in south Sumatra, Indonesia, Lancet, 2002, 360, 58-60.

3 S. Abdulla, I. Sagara, S. Borrmann, U. D’Alessandro, R. González, M. Hamel, B. Ogutu, A. Mårtensson, J. Lyimo, H. Maiga, P. Sasi, A. Nahum, Q. Bassat, E. Juma, L. Otieno, A. Björkman, H.P. Beck, K. Andriano, M. Cousin, G. Lefèvre, D. Ubben and Z. Premji, Efficacy and safety of artemether-lumefantrine dispersible tablets compared with crushed commercial tablets in African infants and children with uncomplicated malaria: a randomised, single-blind, multicentre trial. Lancet, 2008, 372, 1819-1827.

4 M. van Vugt, S. Looareesuwan, P. Wilairatana, R. McGready, L. Villegas, I. Gathmann, R. Mull, A. Brockman, N.J. White and F. Nosten, Artemether-lumefantrine for the treatment of multidrug-resistant falciparum malaria, Trans. R. Soc. Trop. Med. Hyg., 2000, 94, 545-548.

5 E.A. Mueller, M. van Vugt, W. Kirch, K. Andriano, P. Hunt and P.I. de Palacios, Efficacy and safety of the six-dose regimen of artemetherlumefantrine for treatment of uncomplicated Plasmodium falciparum malaria in adolescents and adults: a pooled analysis of individual patient data from randomized clinical trials, Acta Trop., 2006, 100, 41-53.

6 World Health Organization, 2008, http://healthtech.who.int/pq/

7 World Health Organization, 2008, http://healthtech.whoz.int/pq/lists/ mal suppliers.pdf
8 R. Bate, R. Tren, K. Hess and A. Attaran, Physical and chemical stability of expired fixed dose combination artemether-lumefantrine in uncontrolled tropical conditions, Malar. J., 2009, 8, 1-7.

9 G. Sheldrick, A short history of SHELX, Acta Crystallogr., Sect. A: Found. Crystallogr., 2008, 64, 112-122.

10 SAINT, Bruker AXS Inc. , Madison, WI, USA, 2006.

11 G.M. Sheldrick, SHELXS-97, SHELXL-97 and SADABS version 2.05, University of Göttingen, Germany, 1997.

12 O.V. Dolomanov, L.J. Bourhis, R.J. Gildea, J.A.K. Howard and H. Puschmann, OLEX2: a complete structure solution, refinement and analysis program, J. Appl. Crystallogr., 2009, 42, 339-341.

13 B. Janković, S. Mentus and M. Janković, A kinetic study of the thermal decomposition process of potassium metabisulfite: estimation of distributed reactivity model, J. Phys. Chem. Solids, 2008, 69, 1923-1933.

14 T. Ozawa, A new method of analyzing thermogravimetric data, Bull. Chem. Soc. Jpn., 1965, 38, 1881-1886.

15 J.H. Flynn and L.A. Wall, General treatment of the thermogravimetry of polymers, J. Res. Nat. Bur. Stand., 1966, 70, 487-523.

16 T. Ozawa, Kinetic analysis of derivative curves in thermal analysis, J. Therm. Anal., 1970, 2, 301-324.

17 T. Akahira and T. Sunose, Method of determining activation deterioration constant of electrical insulating materials, Res. Rep. Chiba Inst. Technol. (Sci. Technol.), 1971, 16, 22-31.

18 M. Ak, G. C1lg1, F. Kuru and H. Cetisli, Thermal decomposition kinetics of polypyrrole and its star shaped copolymer, J. Therm. Anal. Calorim., 2013, 111, 1627-1632.

19 S. Söyleyici and G. Çılgı, Thermal and kinetic analyses of 2,5-bis(2hydroxyphenyl)thiazolo[5,4-d]thiazole, J. Therm. Anal. Calorim., 2014, 705-709. 


\section{Supplementary material to:}

P.B. Pansuriya, G.E.M. Maguire and H.B. Friedrich,

Structural Characterization and Thermal Properties of the Anti-malarial Drug: Lumefantrine, S. Afr. J. Chem., 2019, 72, 253-262. 
Pramod B. Pansuriya, Glenn E. M. Maguire, Holger B. Friedrich*

School of Chemistry and Physics, University of KwaZulu-Natal, Westville Campus, Durban 4000, South Africa

*E-mail: friedric@ukzn.ac.za

\section{Corresponding author:}

Prof. Holger B. Friedrich

School of Chemistry and Physics, University of KwaZulu-Natal, Westville Campus, Durban 4000, South Africa.

*E-mail: friedric@ukzn.ac.za

Tel: +27(0) 312603107 ,

Fax: +27(0) 312603091
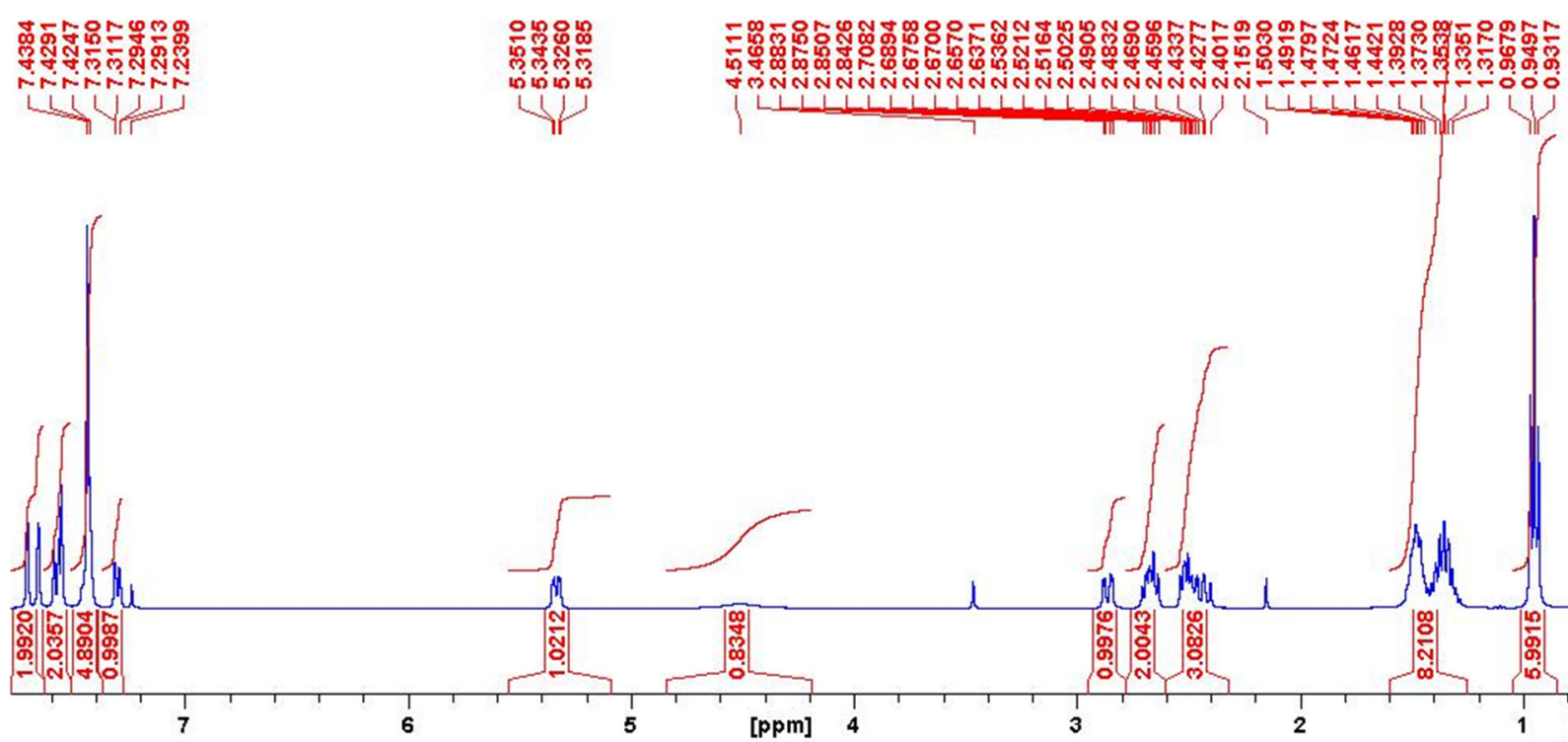

Figure 1: Proton NMR of Lumefantrine. 


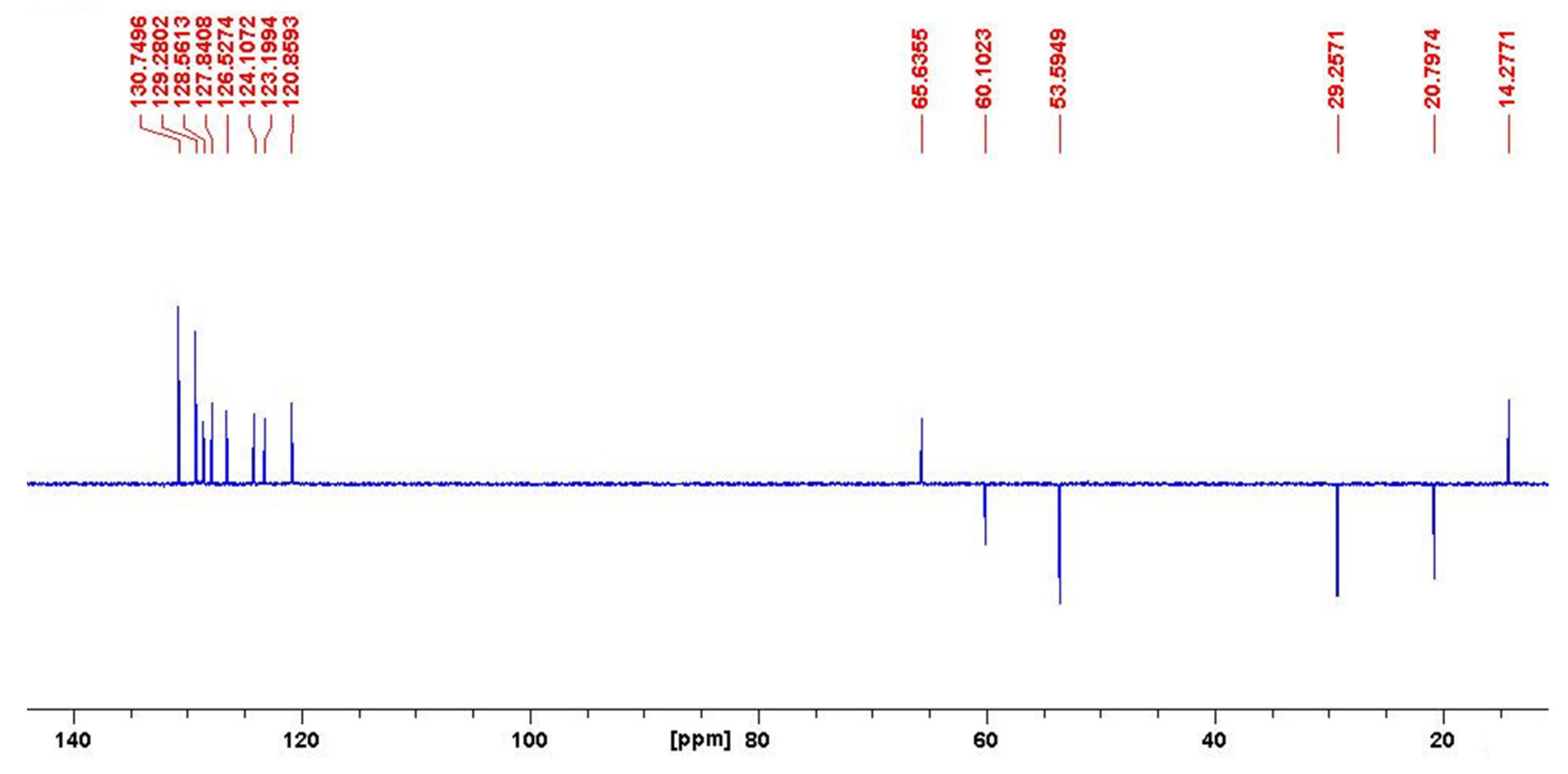

Figure 2: ${ }^{13} \mathrm{C}$ DEPT NMR of Lumefantrine.

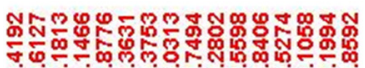

ตำ

IIIIIT)
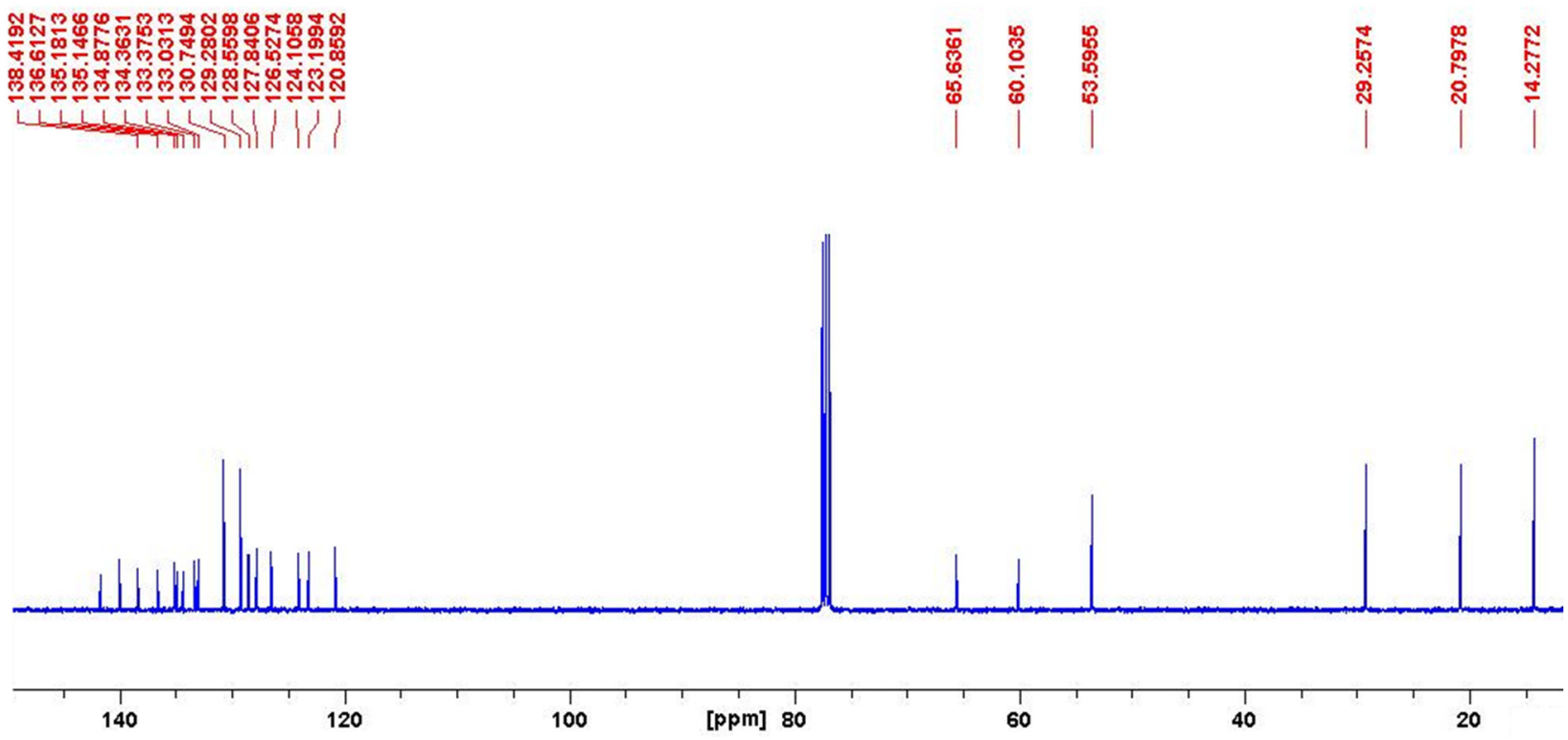

Figure 3: ${ }^{13} \mathrm{C}$ NMR of Lumefantrine. 


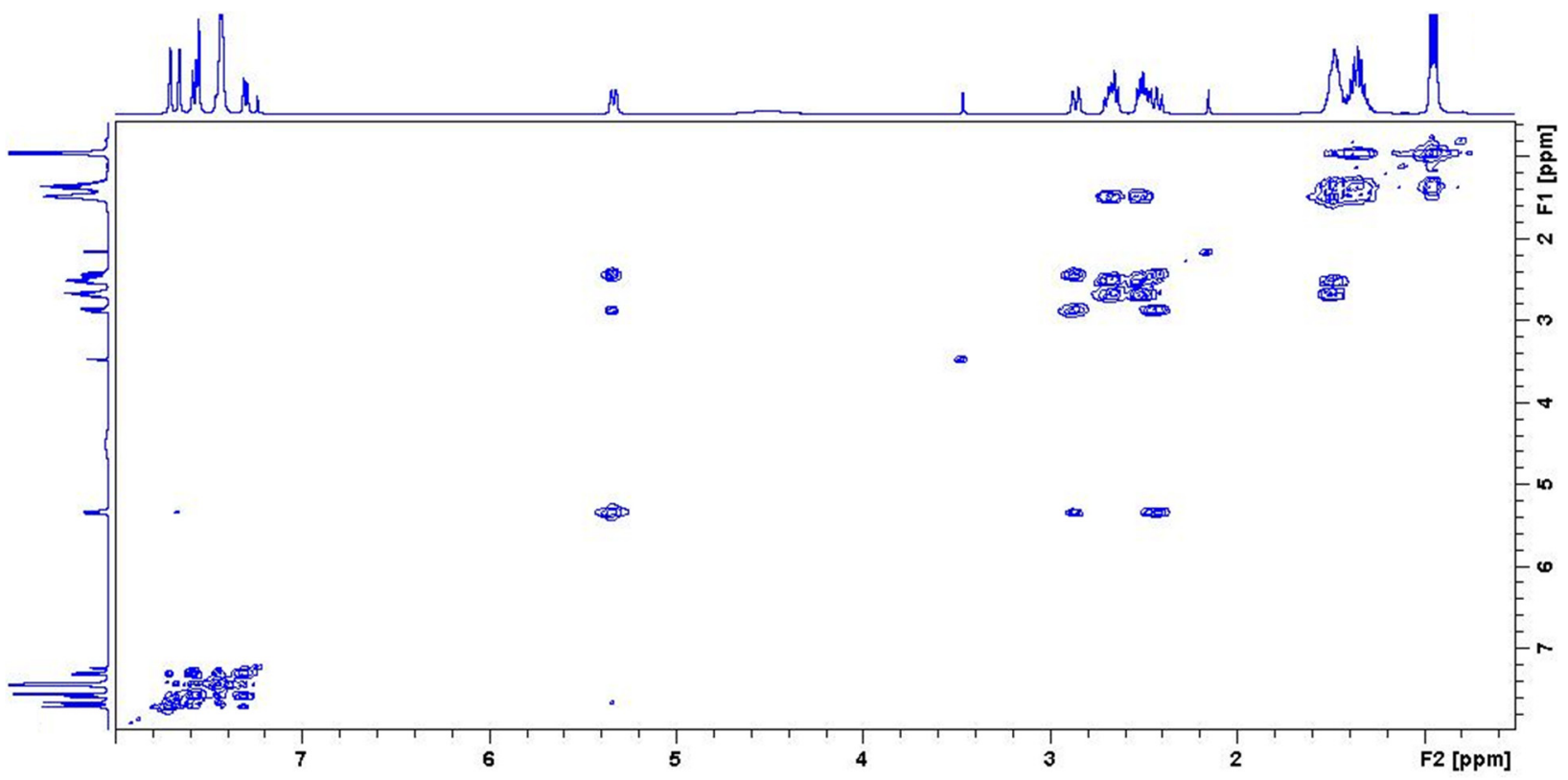

Figure 4: COSY NMR of Lumefantrine.

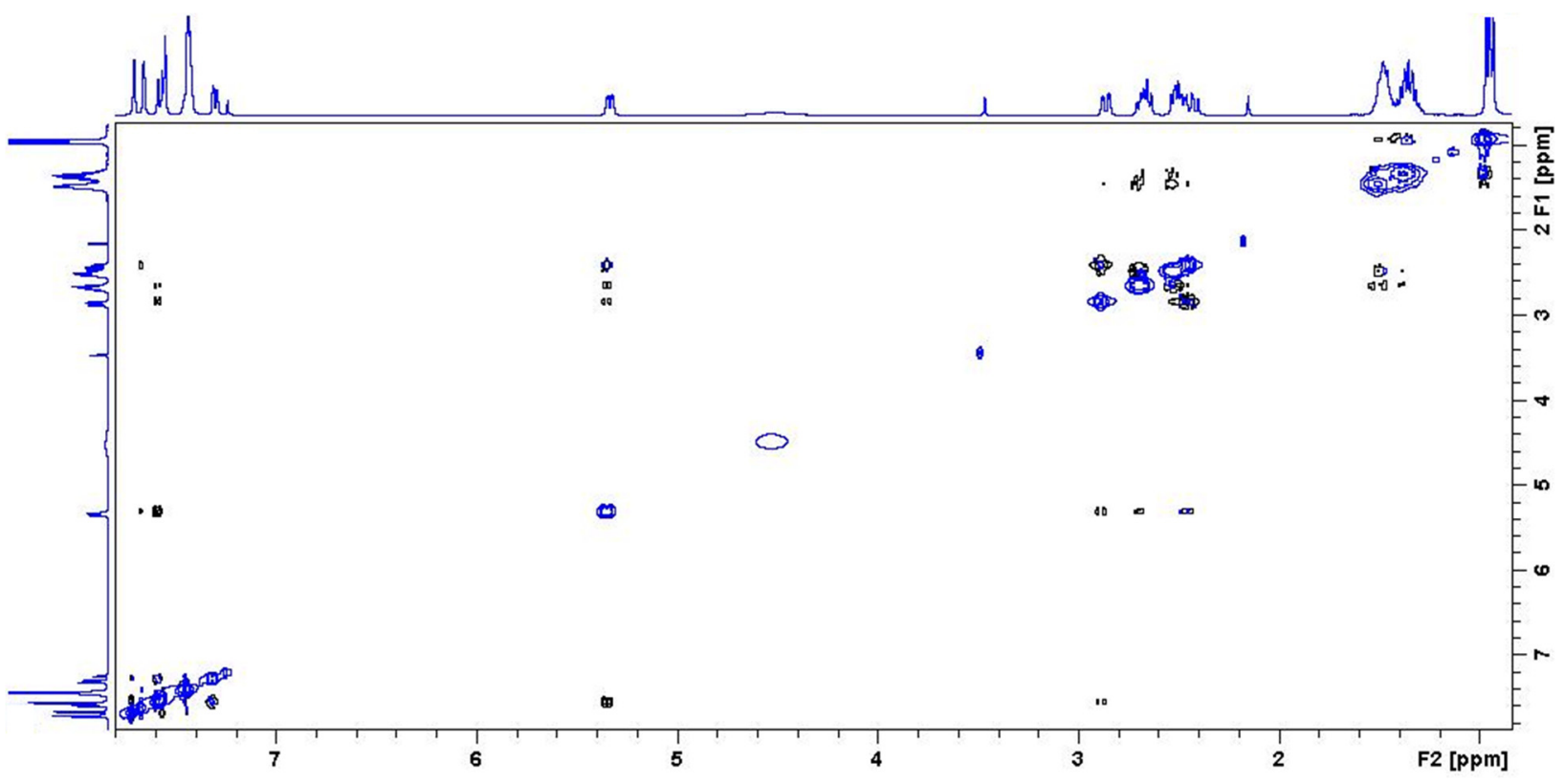

Figure 5: NOESY NMR of Lumefantrine. 


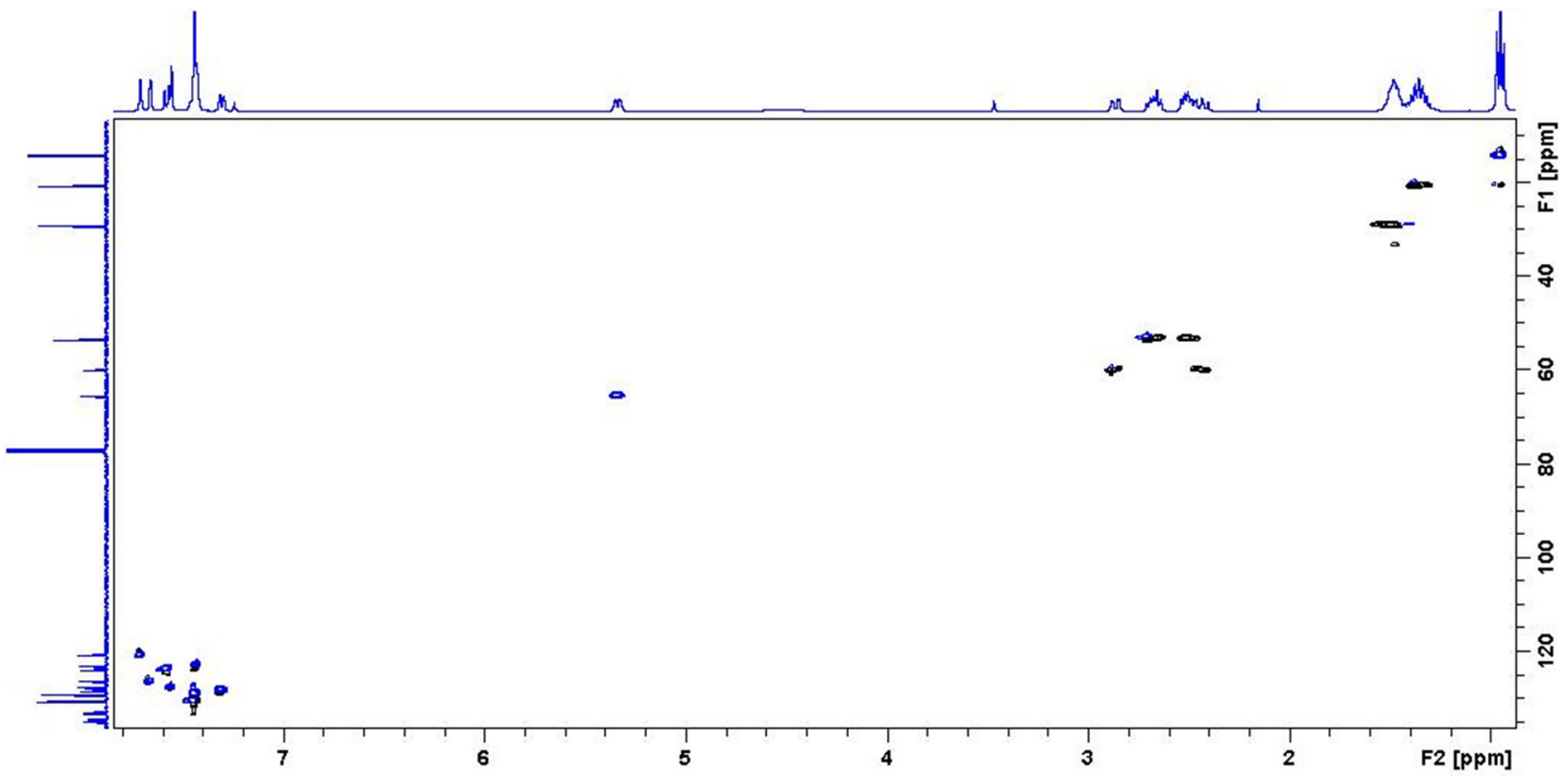

Figure 6: HSQC NMR of Lumefantrine. 